\title{
INTERNET RESEARCH AND ITS PEDAGOGICAL DIMENSIONS
}

\author{
Paula Cordeiro, Vítor Reia-Baptista ${ }^{1}$
}

\begin{abstract}
Internet - et les multimédias en général - semblent assumer aujourd'hui le rôle des contes folkloriques anciens dans leur relation aux mythes, aux religions et aux mystères transcendantaux. Contes modernes, ils font partie intégrante des mythes actuels, avec cette fonction spécifique de «texte ouvert» (tel que défini par Eco) à comprendre à travers nos vies quotidiennes. Une lecture attentive de ces propositions, qui considèrent les documents trouvés sur le Net comme « ouverts », renvoie de façon directe à la méthodologie d'analyse textuelle d'Umberto Eco (développée dans nombre d'autres contextes). Sous cet angle et dans le cadre de la communication humaine, il devient hautement pertinent d'identifier les métaphores épistémologiques que les documents peuvent présenter, et par conséquent de déterminer de quelle manière elles peuvent être observées et utilisées dans le contexte culturel actuel, comprenant la « culture Internet ».

Des chercheurs de l'Université d'Algarve ont tenté de développer différents projets sur le thème de la diversité des identités culturelles, y compris dans le cadre de l'apprentissage des médias et des nouvelles technologies. L'auteur se propose de présenter ici une série d'options pédagogiques pour l'analyse de ces questions d'appropriation et de contexte, liées au phénomène Internet.
\end{abstract}

Recherches en communication, $\mathrm{n}^{\circ} 22$ (2004). 
There is a great need for research and development of multidisciplinary studies about the Internet and the credibility of the information available online. For example, in the field of Cultural Studies, in particular, and in Communication courses, in general, it is possible to develop a corps of analysis which main goal should be to develop different approaches to the research and the organization of information in the Internet. At the University of Algarve we have been trying to develop some projects about themes of cultural identities different and distant to those of the students' own cultural identities in order to discover and study some of the main characteristics of the information available in the Internet and trying to compare them with other characteristics already known from other media and communication contexts. These students also study the risks of the Internet, namely in what respects the information credibility and the adequate contextualization of that information, as well as the correct identification of information sources and channels.

We present here some different pedagogical propositions of analysis.

\section{The Internet as a new communication platform}

The digitalisation is the basis for the modern communication, presenting a technological system of digital treatment and information control programs.

For its capacities of production and archive, its social system and economic characteristics, the Internet and its components (with prominence for the World Wide Web), must be included in the set of the mass media, enlarging its capacity to extend the categories previously defined for the communication technologies.

The Internet must be faced as a communication platform, a galaxy in permanent expansion and reorganization, which allows the allotment and the exchange of information between thousand of people, through conventional lines of telephone, optical-fibre, satellite links and microwaves. Its presence became so usual that it is in some cases, ubiquitous and operates substitution experiences of the man for the machine, on behalf of the innumerable computers and software possibilities. Has come to become part of the every day life, for the easiness access and 
information consults, but and essentially, for the services that provides, of which web is one of the multiple available instruments :

The email is a remarkable process, to send in a fast and cheap way, information for short or long distances.

Newsgroups are structuralized forums on the most varied subjects, where the users can discuss and receive information about their favourite subjects on personal email.

The Internet Relay Chat allows the conversation in real time on the most varied subjects, through written messages that are grouped in diverse channels, available for who may it find it in the net.

The File Transfer Protocol is a transference method of files, free programs and public domain programs, from one computer to another.

The Internet congregates an ample set of services from which is can be detached, for this work, the World Wide Web. For its characteristics, the Internet surely will become the bigger base of information, and the web, the main support for the new media and services that are starting to develop. Essentially used as communication channel of electronic messages, the web contains a series of useful information, set by individuals, institutions, governments, associations and all types of commercial organizations.

Beyond the boundless and instantaneous allotment of the data, the Internet came to develop new fields for the economy, related with new communication instruments and the access to the communication and information industries. It was devoted as a complement to the media activity and as an information source for the individuals that use it on a daily basis ${ }^{2}$.

The mass media established the traditional idea of message transmission from an emission centre to a plurality of receiving individuals, contrary to the personal and immediate communication. The Internet came to redefine this meaning through the incorporation of a communication system that can comprehend the media expressive systems previously known, and the individual easiness to produce online contents. The Internet is the "net of the nets", in organical development where the source of the messages no longer has a steady and explicit character, transforming the method of production and reception, available at any moment, accessible in any place, at reduced costs and richer offer. 


\section{The Internet as a World Wide Open Work}

This proposition that considers the internet documents, or texts, as open works refers directly to the methodological strategy of text analysis once presented by Umberto Eco, before we could even dream about the internet, but that can be defined as the analysis of the relationship between the contemplation and the utilization of any «work of art», or «text», or «communication document» with the qualities of an «open work»- L'oeuvre ouverte ${ }^{3}$.

This notion of «open work» is, of course, also influenced by Eco's later writings developing the subject in relation to the notion of «absent structure» ${ }^{4}$ and to the structural role of «metaphor» in a broader sense of «Semiotics and the Philosophy of Language» ${ }^{5}$.

The implications of such a relationship, that Umberto Eco called the «poetics of the open work», were already the object of study in his early book L'oeuvre ouverte and introduced a complementary notion of the work as a pedagogical metaphor of knowledge, which can be summarized with the following citation :

...si une forme artistique ne peut fournir un substitut de la conaissance scientifique, on peut y voir en revanche une métaphore épistémologique : à chaque époque, la manière dont se structurent les diverses formes d'art révèle - au sens large, par similitude, métaphore, résolution du concept en figure - la manière dont la science ou, en tout cas, la culture contemporaine voient la réalité. 6

For this proposition, it is of great relevance to identify the epistemological metaphors that the documents can represent within the field of human communication and consequently to determine how those metaphors can be contemplated and utilized within a contemporary cultural context, like the «internet culture».

Some of these metaphors cannot be analyzed with the traditional instruments of literary criticism, which, despite their unfitness for their actual narrative forms, have been used too many times as instruments of traditional literary criticism and are therefore marked as such. To approach the pedagogical value of the internet multiple text imagery requires more than a mere identification of the tenors and the vehicles in 
the metaphors. It requires, essentially, the identification of functions and themes, patterns of information structure, signs and contexts of signification. This means, in fact, that sometimes we are not too far away from Vladimir Propp's study of the folk tales, which he defined as a "study of the folktale according to the functions of its dramatis personae"7.

The internet metaphors (and the modern multimedia in general) assume, indeed, the role of the ancient folk tales in their relationship to myths, religion and transcendental mysteries. They are modern tales and parts of modern myths with specific functions, and we can find some structural similarity between these and those analyzed by Propp in the folk tales, which he formulated as follows in his first thesis and which we could easily adopt as a point of reference for the narrative nature of the internet multimediatic functions :

"Function must be taken as an act of dramatis personae, which is defined from the point of view of its significance for the course of action of a tale as whole" ... "Functions serve as stable, constant elements in folktales, independent of who performs them, and how they are fulfilled by the dramatis personae. They constitute the components of a folktale"

Unfortunately, we cannot apply so easily to the internet Propp's second and third thesis. The number of functions known to the multimediatic components is not necessary limited, even if it can, apparently, be so in the case of the most closed genres and structures, nor is the sequence of functions always identical. Quite the contrary, the internet multimediatic texts, in their quality of open works, are examples of nonidentical unlimited sequences of functions. They are, in fact, «heretical» approaches to the folk tales, but tales nevertheless. This means that we also can lean on some theoretical support from Propp's formalistic and structural approach, but that we cannot completely follow his method for the analysis of our material. However, and although it has not been or aim to accomplish a morphology of the internet «tales» (which, per se, is a very interesting task for future research, it seems, nevertheless, that we could use some of Propp's functional nomenclature to designate the most relevant functions in some internet genres, exactly as it has been done for other media, namely in the field of film studies.

The insufficiencies in the methods of traditional literary criticism and of formal-structuralism when applied to multimedia and hypermedia analysis may be compensated with elements that determine another specific matter of expression that embodies the virtual metaphors imagery. For this purpose it is especially interesting to determine 
the metaphoric implications of the notion Equivalence, and here we could borrow some of the work that has been done in the field of photographic studies, namely by Susan Sontag in relation to the notion of «photographic equivalents» by the great north American photographer Alfred Stieglitz :

"Equivalents", that is, statements of his (Stieglitz) inner feelings." ... " Photography is the paradigm of an inherently equivocal connection between self and the world - its version of the ideology of realism sometimes dictating an effacement of the self in relation to the world, sometimes authorizing an aggressive relation to the world which celebrates the self ${ }^{9}$.

The reading possibilities of these texts are in fact wide open and it is necessary to train the reader (the user) to find the patterns of narrativity that may exist in the text structure of real referents, their metaphors and/or equivalents. Or, last but not least, to understand the function of their absence. When doing this, we find ourselves usually in a learning process, in the widest sense of the expression, and that is why the pedagogical dimensions that is involved and carried in the different multimedia channels turn usually to be of great effect, especially if the readers are not quite aware of them.

The Internet facilitates the information research, but it requires a redoubled attention in the verification of the information. The credibility and authenticity of the data found in the Internet is one of its greater problems, which is generally ignored in favour of a thought that considers the present information free from errors, and therefore, reasonable for gratuitous use without any type of verification. The diversification of the production and the absence of evaluation filters, express a redistribution of data, less conditional and therefore keener to suffer from all type of negative influences.

The databases and the Internet contents allow the access to innumerable information, in a simple and fast way, but they can become useless, without a previous ability to use them. Moreover, the easiness and free access to all sort of information do not mean that the user will be able to contextualize it, in face of its cultural universe. This possibility is, in such a way, as important as the acquisition of the necessary skills to look up and to know what to make with the collected data. The technological system of the Internet and its auto-legitimacy, dissolve an extensive set of questions and inequalities in the access to the informa- 
tion, transforming the technological performance into the guarantee of content veracity.

The democratisation of the communication channels discloses the capacity to exceed the receiving condition, to an individual reflection allowing also an individual leading form of participation, while individual user who interacts through the multimedia channels.

In this context we may now refer to the Educaunet project.

Educaunet ${ }^{10}$ is a critical education programme, teaching about Internet and its possible risks. It's being developed within several European countries to implement an awareness campaign and training sessions for educational publics. Its educational model advocate an active commitment to risk-taking, based on a set of pedagogical tools and activities produced in close cooperation with all the participants. The major objectiv is to train the children's ability to assess and become aware of the risks when using the net.

The Portuguese approach to new media is rather different from other European countries, specially the Northern European ones, where children already are familiar to the Internet and frequently use it, at home or school. In those countries, the Educaunet project focuses especially on the Internet risks, because the challenges are already known. In Portugal, we also have to focus on the risks and the challenges, since many children and young people have never used the Internet, or have only done it a few times. A great part of the Portuguese children does not have computer linking to the Internet at home, thus making an Internet use at school, with limitation of time.

However there is a common belief considering that through the use of the computer the social differences may decline, this is not so simple, since the circulation of the information through the net is still not universalised, presenting two distant features - development and exclusion -, in the access and the capacity to operate the information channels. There's a global production and diffusion of the information, which does not find parallel on the side of the reception, in an age that can easily keep out those who don't dominate the techniques, languages and devices used to communicate. The online communication has produced a new specific net culture, which came to introduce new patterns of communication within the social space. This is, in fact cultural forms of absence in a structural sense. 


\section{The Internet as an Absent Structure}

This proposition is an exercise that, isolated from the organic structure of the object, may function as a source of information in direct connection with the study of the its most important components and their respective equivalents of virtual transfiguration, serving as an instrument of evaluation, comparison and assessment of the information flow connected to content and form of the multimediatic «themes», or genres, and to the group of functions assumed by the characters within the themes. They are generally very difficult to define because their number varies with the nature of the themes and, sometimes, even with their apparent absence in the main structure. In this context we should be especially interested in those that embody the requisites of the moralities, abstractions of vice and virtue and other ethical values, or those that in their «heretical» relationship with the themes make their contribution to generate a sense of absence of values. And again, it can be very important to be able to identify which functions, from the structure of the folk tales, are coming out of such a fragmentary structure.

For example, the titles, that according to the notion of the «open work», are absolutely determinant factors in the interpretation processes, can open or close, turning it into virtual absence, the structure of a work completely.

The pedagogical dimension of such devices, may be a result of the character of their structural function within the «open work», and it may assume, in fact, some aspects of education values that can be developed within the process of confrontation between the expectations, or apparent reasons, and the answers (or the lack of them) that strike the reader, or the user. This process includes the manipulation of thematic and semantic items and, generally, it is an embedded way of conditioned literacy and pedagogical awareness. We can say that the «poetics of the open work» may constitute the pedagogical dimension of such a reading process, either it is wide open in its significance or apparently absent of signification. Luis Buñuel's comments on the neo-realist film understanding constrictions could be used to help us understand some of the constrictions within the internet approach and its pluralism of signs and of contexts of signification which turns the semiosis behind the «obvious» meanings, their denotative and connotative paradigms, into a useful instrument that offers some accuracy to the this kind of analysis, and although Buñuel hated such jargon, it was he 
himself who exposed this problem as an argument against the "monolithic" views of the neo-realist cinematography and of the daily media, and we could add - the internet where apparently «a glass is a glass and nothing more» :

... this same glass, contemplated by different beings, can be a thousand different things, because each one charges what he sees with affectivity; no one sees things as they are, but as his desires and his state of soul make him see. I fight for the cinema which will show me this kind of glass, because this cinema will give me an integral vision of reality, will broaden my knowledge of things and people, will open up to me the marvellous world of the unknown, of all that which I find neither in the newspaper nor in the street ${ }^{11}$.

In fact we should also be fighting for the world wide media that could give us such an integral vision of reality and therefore broaden our knowledge.

\section{Notes}

1 Ciências da Comunicação - Universidade do Algarve, Portugal

2 The Internet is frequent to be used as source that spreads out the information or distributes contents, such as the transmission of conferences, concerts or congresses, complementing the information offered by the radio and the other media.

3 ECO, U., L'œuvre ouverte, Paris, Éditions du Soleil, 1965.

4 ECO, U., Den Frånvarande Strukturen, Lund, Bo Cavefors Bokförlag, 1968.

5 ECO, U.,, Semiotics and the Philosophy of Language, London, Macmillan Press, 1984, pp. 87-129.

6 ECO, U., L'oeuvre ouverte, op. cit., p. 28.

7 PROPP, V., "Morphology of the Folktale", International Journal of American Linguistics, Vol. $24 \mathrm{Nr}$ 4, Bloomington, Indiana University Research Center in Anthropology, Folklore, and Linguistics, October 1958, p. 28.

8 Ibid., p. 20.

9 SonTAG, S, On Photography, New York, Penguin Books, 1973, p. 123.

10 Find more about this project at http ://www.educaunet.org

11 As cited in REIA-BAPTISTA, The Heretical Pedagogy of Luís Buñuel, Lund, Lund University, Litteraturvetenskapliga Inst. Depart. of Drama-Teater-Film, 1987, p. 9. 
